\title{
Yet more population modelling
}

\section{Robert H. Smith}

Modelling Fluctuating Populations. By R.M. Nisbet and W.S.C. Gurney. Pp.379. ISBN 0-471-28058-5. (Wiley: 1982.) $£ 19.50, \$ 47.50$.

THE APPEARANCE of yet another book on population modelling written by yet more mathematicians/physicists/engineers with an enthusiasm for ecology is, on a probabilistic basis, unlikcly to arouse much interest amongst ecologists. With a few notable exceptions, such texts are mostly regarded as excuses for mathematical selfindulgence and are seldom read by ecologists, apart from those of us unfortunate enough to be asked to review them. However, Modelling Fluctuating Populations is exceptional in more than one way, and provided me with an unexpected pleasure; I enjoyed almost all of the book and found every chapter valuable.

Although there have been many books on mathematical ecology since Lotka's seminal contribution Elements of Physical Biology (Williams \& Wilkins, 1925), few are memorable. May's Stability and Complexity in Model Ecosystems (Princeton University Press, 1973) is an exception and must be regarded as one of the most important books in the field; as well as some new insights into the subject matter of the title, the book provided a lucid account of the mathematical techniques used by physicists to analyse equations of motion. The main shortcoming of May's book was the deliberate omission of stochastic models, apart from the use of Kolmogorov's diffusion equation to represent a particular type of environmental variability.

In Modelling Fluctuating Populations, Nisbet and Gurney have given a thorough and rigorous account of the techniques available for investigating the dynamic properties of models, both deterministic and stochastic. Just as important, they devote some space to the problem of formulating the most appropriate mathematical representation of a process. Most ecologists will find the mathematics hard to follow, but not impossibly so; and at least the authors do not pretend that difficulties both in manipulation and interpretation do not exist.

The presentation of text and equations is of a very high quality, but unfortunately the same cannot be said of the lettering of the figures, many of which call for the use of hand-lens - in this respect the book is more suitable for the field ecologist than the theoretician. Some of the worst examples are where material has been taken from other publications and photoreduced (e.g. Figs 2.15 and 2.16), but there are many other such instances among the figures drawn especially for the book (e.g. Figs 2.9, 5.8 and 7.13). It is a pity that an otherwise excellent production is marred by such an elementary but important flaw.

Like many before them, Nisbet and Gurney find themselves in deep water when they try to put their ecological models into an evolutionary context. Stability is a property of populations and is not a direct consequence of natural selection, and Nisbet and Gurney are honest enough to invoke group selection explicitly when they suggest why limit cycles might be rare in nature. Leaving aside the difficult question of what conditions are necessary for group selection to be of any importance, the authors have a clear penchant for point equilibria rather than stable limit cycles, and most of their linear approximations require the existence of a stable equilibrium point. However, they do not shirk the task of coping with non-linearity where necessary as evidenced by their interesting treatment of Nicholson's blow-fly in Chapter 8. This chapter, and the other two case-studies, are very worthwhile and in themselves provide adequate justification for the rest of this excellent book.

Robert $H$. Smith is a Lecturer in Applied Zoology at the University of Reading.

\section{The evolution of landscapes}

\section{J. Rose}

Climatic Geomorphology. By Julius Büdel. Pp.528. Hbk ISBN 0-691-08294-4; pbk ISBN 0-691-08295-2. (Princeton University Press: 1982.) Hbk £40.62, \$65; pbk £15.31, \$24.50.

OVER the past few decades geomorphology in most English-speaking countries has primarily dealt with the interaction between particular surface processes and the resisting surface materials. For the sake of practicality most of these studies have been concerned with isolated problems, river-channel bedforms or hillslope hydrology for example. The results of this work have been summarized in systematic texts such as Sugden and John's Glaciers and Landscape (Edward Arnold, 1976) and Schumm's Fluvial System (Wiley, 1977).

Similarly, where English-speaking geomorphologists have investigated the evolution of landscapes through time they have largely adopted an interdisciplinary approach within the framework of the Quaternary; again, these studies have been the subject of significant texts such as Goudie's Environmental Change (Oxford University Press, 1977) and Bowen's Quaternary Geology (Pergamon, 1978). An explanation for the wider span of landform assemblages and integrated landform development has received little attention other than in Pitty's Introduction to Geomorphology (Methuen, 1971), and this has been far from widely understood. Climatic Geomorphology by Jülius Büdel, now Emeritus Professor of Geography at Würzburg, Germany is an unashamed attempt to remedy this deficiency.

Büdel's view of geomorphology consists of an investigation of the processes involved, which he calls "active geomorphology"; an appreciation of the role and magnitude of contemporary landscape alteration, which he terms "dynamic geomorphology"; and the global stage upon which the processes take place, to which he gives the title "climato-genetic geomor- phology". "Climatic geomorphology" is the foundation for all these approaches and is the thesis of this book.

In many respects Climatic Geomor phology is a personal expression of over 50 years' geomorphological experience from all regions of the globe. Although there are some distinctive personal traits, such as a degree of contempt for the isolated studies that have dominated geomorphological research in the English-speaking world, it is far from out of date, with some 38 per cent of the references published in the decade before it went to press, and far from parochial with 19 per cent of the references in the English language. The book is divided into three parts: an introductory section which explains the geomorphic processes, interactions and spheres of operation in a concise but illuminating fashion; a main body of text which reviews the global landscape in terms of morphogenetic regions; and a series of case-studies from selected areas to illustrate the principles so developed. This last section gives particular emphasis to aspects of the central European landscape.

To a considerable extent, Büdel's approach to geomorphology, and hence the rationale behind his book, can be understood in terms of his desire to explain the landscape of central Europe with geomorphologically active Alpine mountains and geomorphologically quiescent incised valleys and upland plains. The mountain and glacial morphogenetic zones he considers to be globally ubiquitous and therefore receive little attention. The incised valleys are the goal of his study of "ectropical" regions and the results of fieldwork in Spitzbergen lead him to believe that bedrock disruption and disaggregation by ground ice beneath river channels provide the mechanism for "excessive valley deepening". Although the argument is clear and well illustrated it is, in my opinion, far from convincing and much of the evidence put forward by Büdel for con- 